RESEARCH ARTICLE

\title{
Upper Airways Modification Following Mandibular Thrust Treatment
}

\author{
Bisconte P, Fusco E, Farronato M, Farronato $G$ and Lombroni $L G^{*}$
}

Department of Orthodontics, Fondazione IRCCS Ca' Granda - Ospedale Maggiore Policlinico, Milano, Italy

*Corresponding author: LG Lombroni, Department of Orthodontics, Fondazione IRCCS Ca' Granda - Ospedale Maggiore Policlinico, Milano, Italy, E-mail: lidialom@hotmail.it

\begin{abstract}
Aim: The aim of the study is to evaluate morphological changes in upper airways in patients undergoing therapy with removable functional orthopedic devices used in the treatment of the II skeletal classes by mandibular retraction.

Materials and methods: 15 patients treated with mandibular thrust have been selected and the digital images of later-lateral teleradiographs prior to treatment and subsequent treatment have been retrieved. Cephalometric analyzes were performed using the Delta-Dent software.

Results: The cases treated with Occlus-o-Guide (OG) compared with the cases treated with activators of Andresen (A) and Frankel $(F)$ had a greater effect on decreasing ANB, greater inhibition of maxillary protrusions, a general increase in Ar-Pog; Cases treated with $\mathrm{F}$ showed a slight increase in the angle of divergence with respect to cases treated with A and lower mandibular forward stimulation than Andresen activator treated cases, a greater increase in the depth of the upper portion of the oropharynx with activator of $A$ and F compared to OG.
\end{abstract}

Conclusions: The treatment of skeletic classes II by mandibular retrusion involves an increase in the postero-front extension of the pharynx. The effects of the 3 mandibular propulsions are superimposable.

\section{Keywords}

Upper airways, Occlus-O-Guide, Frankel, Andresen, Thrust treatment

\section{Abbreviations}

UAS: Upper Airway Stenosis; OSAS: Obstructive Sleep Apnea Syndrome; CBCT: Cone Beam Computed Tomography; CPAP: Continuous Positive Airway Pressure; RPE: Rapid Palatal Expander; AS: Start Age of Treatment (years); AE: End Age of Treatment (years)

\section{Introduction}

Upper Airway Stenosis (UAS) causes considerable functional repercussions on the stomatognathic and inferior airways. The correlations between stomatognathic system and respiratory function and the different evaluation methods of the latter have been topics often studied by the Ortognatodontic School of the University of Milan. In an article published in 1985 [1] Prof. G. Farronato and Prof A. Salvato presented the results of a study on two distinct samples, the first comprising pediatric patients "nasal respirators", the second age pediatric patient "oral respirators". In particular, the results of the rhinomanometry performed on these patients were compared with those of the cephalometric analysis of their skull teleradiographs in latero-lateral and postero-anterior projection. In a recent article [2] of 2005, we analyzed changes in the UAS after Andresen monoblock therapy in patients with skeletal class II and Obstructive Apnea Syndrome Sleep (OSAS); In this case the evaluation was done by Cone Beam Computed Tomography (CBCT) tomography.

The skeletal II class is generally associated with a mandibular retraction condition which is for functional problems related to upper airways [3]. According to Muto, et al. [4], mandibular retraction, reduced mandibular body length and mandibular growth in post rotation can lead to a reduction in UAS's perpetuity. Study of UASs and their correlation with mandibular position and size is of utmost importance in the field of orthodontic diagnosis also with regard to Obstructive Sleep Apnea Syndrome (OSAS), frequently treated with a mandibular advancement, orthopedic or surgical procedure, depending on the therapeutic timing. If the space of the

Citation: Bisconte P, Fusco E, Farronato M, Farronato G, Lombroni LG (2017) Upper Airways Modification Following Mandibular Thrust Treatment. Int J Oral Dent Health 3:048. doi.org/10.23937/24695734/1510048

Received: July 28, 2017: Accepted: September 28, 2017: Published: September 30, 2017

Copyright: (c) 2017 Bisconte P, et al. This is an open-access article distributed under the terms of the Creative Commons Attribution License, which permits unrestricted use, distribution, and reproduction in any medium, provided the original author and source are credited. 
cervical spine and the mandibular body decreases, the tongue and the soft palate may take a very posterior position, increasing the possibility of an incongruous respiratory function and, during the night, of snoring and OSAS [2,5-7].

The treatment of OSAS obviously involves normalizing breathing during sleep, firstly through appropriate hygienic measures (taking a proper body position during sleep, excessive weight loss), and possibly using CPAP (Continuous Positive Airway Pressure), with surgical procedures or by means of functional devices (oral devices) whose purpose is to increase the volume of UAS by introducing mandibular advance $[8,9]$.

The aim of our study is to evaluate, through radiographic analysis and a cephalometric study, changes in the Rhino-Oro-Pharyngeal airways following therapy with different types of orthopedic-functional equipment, attributable to the category "mandibular thrusters", used in the treatment of the skeletal mandibular retrapping classes, in particular we treated patients with Andresen activator, the function regulator Frankel type I or II and the "Occlus-O-Guide", looking for any differences between the different Patient groups [10-12].

\section{Materials and Methods}

We conducted a retrospective study on patients with skeletal class II (ANB $>4^{\circ}$ ), for mandibular retrusion treated at the Department of Orthodontics at the "Maggiore Policlinico" Hospital in Milan and selected after an accurate clinical record study aimed at Research of patients currently in orthodontic multibrackets therapy and which had previously been subjected to intercepted and functional orthopedic therapy with rapid expansive palatal and subsequent removable mandible thruster.

Over 105 clinical records of patients in orthodontic multibrackets, 63 were analyzed referring to patients previously treated for a mandibular skeletal II class problem.

The inclusion criteria of our research were:

- Patients who are not affected by craniofacial malformations and/or syndromic conditions.

- Patients with no Obstructive Sleep Apnea Syndrome (OSAS) or other relevant respiratory diseases.

- Patients with mixed respiration, predominantly oral, clinically highlighted by the search for Gudin test (compress alternately for 1 second the wings of the nose of the patient; if oral breathing is predominant, there is no reflected response to enlargement of the nostril) and Rosenthal test (twenty respiratory acts first with the two nostrils, then with each nostril separately; If the patient is an oral respirator it opens its mouth before the end of the test, while the pulse and breath increase in frequency).

- Patients undergoing intercepted and functional or- thopedic therapy comprising only a rapid palatal expansion stage (implemented with ERP type Hyrax cemented on the first permanent molars or deciduous seconds molars) followed by a mandibular propulsion phase carried out with Andresen activator or function regulator of Frankel type I or II or Occlus-O-Guide.

- Patients who had radiographic documentation suitable for the study (teleradiography of the skull in latero-lateral projection before the beginning of the interceptional and orthopedic-functional therapy phase and a subsequent one at the end of this phase).

15 patients ( 9 females, 6 males) were selected, divided into 3 samples:

5 patients treated with RPE and activator of Andresen

-As1:11 -Ae1:13

$-A s 2: 12$

-Ae2:15

$-A s 3: 12$

-Ae3:14

$-A s 4: 12$

$-A e 4: 15$

$-A s 5: 12$

-Ae5:14

Middle As: 11.8

Middle Ae: 14.2

5 patients treated with RPE and Frankel type I or II:

-As6:9 -Ae6:10

$-A s 7: 8$

$-A e 7: 13$

-As8:12

-Ae8:14

-As9:10

-Ae9:14

-As10:11

-Ae10:16

Middle As: 10

Middle Ae: 13.4

5 patients treated with RPE and Occlus-O-Guide:

$\begin{array}{ll}-A s 11: 8 & -A s 11: 10 \\ -A s 12: 10 & -A s 12: 11 \\ -A s 13: 9 & -A s 13: 12 \\ -A s 14: 8 & -A s 14: 12 \\ -A s 15: 7 & -A s 15: 10\end{array}$

Middle As: 8.4

Middle Ae: 11

The mean age at start of treatment was 10 years while the mean age at the end was 13 years. The digital images of teleradiographs prior to treatment (TO) and subsequent treatment (T1) have been retrieved (Figure 1 and Figure 2).

Cephalometric analysis was performed using the Delta-Dent (Outside Format) cephalometric analysis software. On our project and request was compiled by computer technicians a specific cephalometric analysis including the main parameters of the analysis of Gianni [5] and other functional parameters to describe the depth of rhino-pharyngeal and oro-pharyngeal. The other parameters are the 3 lines parallel to the SN plane passes for $\mathrm{C} 1, \mathrm{C} 2, \mathrm{C} 3$. 


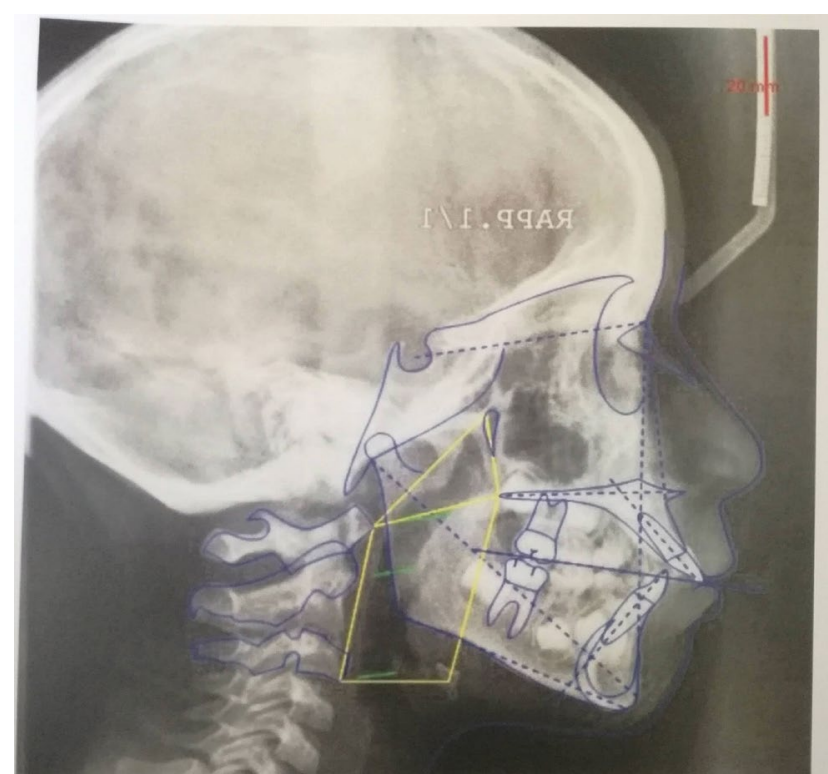

Figure 1: Teleradiographs prior to treatment (T0).

The line parallel to the $\mathrm{SN}$ plane passing through $\mathrm{C} 1$ intersects the posterior pharyngeal wall and the frontal pharyngeal wall at the following points:

\section{OSP: Upper Posterior Oropharyngeal}

\section{OSA: Upper Anterior Oropharyngeal}

The line parallel to the $\mathrm{SN}$ plane passing through $\mathrm{C2}$ intersects the posterior pharyngeal wall and the frontal pharyngeal wall at the following points:

OMP: Medial Posterior Oropharyngeal

\section{OMA: Medial Anterior Oropharyngeal}

The line parallel to the SN plane passing through $\mathrm{C3}$ intersects the posterior pharyngeal wall and the frontal pharyngeal wall at the following points:

\section{OIP: Lower Posterior Oropharyngeal}

\section{OIA: Lower Anterior Oropharyngeal}

Finally, the area of a triangle having the vertices $\mathrm{C} 1$, $\mathrm{Pt}$, Snp of a quadrilateral with the vertices $\mathrm{C} 1$, Snp, $\mathrm{Hy}$, $\mathrm{C} 3$ and the summation of the above mentioned areas have been calculated.

All cephalometric pathways were performed three times by the same operator at two-week intervals and for each parameter the mean value was calculated from the 3 values found.

The collected data were subjected to statistical analysis. The mean and standard deviation was calculated for each parameter studied within each sample, and mean and standard deviations were also calculated by considering all 3 sample patients together. A specific statistical analysis was also carried out of the variations that affected each angular or linear parameter; Even in this case the mean and standard deviation was computed and the data were compared in pairs (monoblock vs. Occlus-O-Guide, Frankel vs. monoblock, Frankel vs.

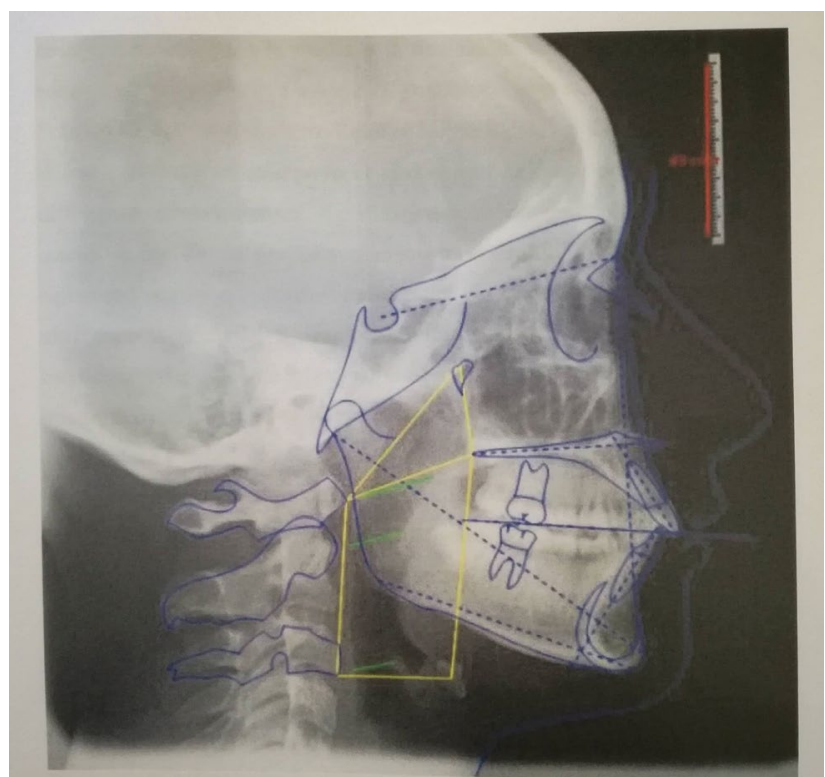

Figure 2: Teleradiographs subsequent treatment (T1).

Occlus-O-Guide) by applying Student's test as there It was wondered whether it was possible to define statistically significant differences with respect to variations and therefore whether one of the three groups showed better results with respect to the increase in airway depths higher than the other two.

All data of all three groups were compared using the Pearson correlation index $(r)$ useful to determine if the variables studied are associated or not and their possible degree of association.

\section{Results and Discussion}

The results of the cephalometric analyzes performed are summarized in the following tables: For each parameter, there are angular or linear values before RPE and mandibular thrust, after treatment end and variation ( $\Delta$ ) (Table 1, Table 2 and Table 3).

\section{We observed about skeletal variations:}

- A greater effect on the decrease of the ANB angle in the cases treated with Occlus-O-Guide compared to cases treated with activator of Andresen and Frankel I or II (average values of $\Delta$ relative to ANB are $-3.04^{\circ}$ respectively, $-2.24^{\circ},-2.12^{\circ}$ ).

- Increased inhibition of maxillary protrusions in patients treated with Occlus-O-Guides $\left(\Delta=-1.66^{\circ}\right)$ compared to patients treated with Andersen monoblock $(\Delta=$ $\left.0.68^{\circ}\right)$; Student's test in this case showed a statistically significant difference $(p=0.028)$.

Increased mandibular forward stimulation in patients treated with monoblock $\left(\triangle \mathrm{SNB}=2.88^{\circ} ; \triangle \mathrm{SND}=\right.$ $\left.2.64^{\circ}\right)$ compared to patients treated with Frankel ( $\triangle \mathrm{SNB}$ $\left.=1.38^{\circ} ; \Delta \mathrm{SND}=1.72^{\circ}\right)$ and Occlus-O-Guides $(\Delta \mathrm{SNB}=$ $1.36^{\circ}, \triangle \mathrm{SND}=0.98^{\circ}$ ).

- An overall increase in Ar-Pog (greater in patients treated with activator, an average increase of $8.05 \mathrm{~mm}$ ). 


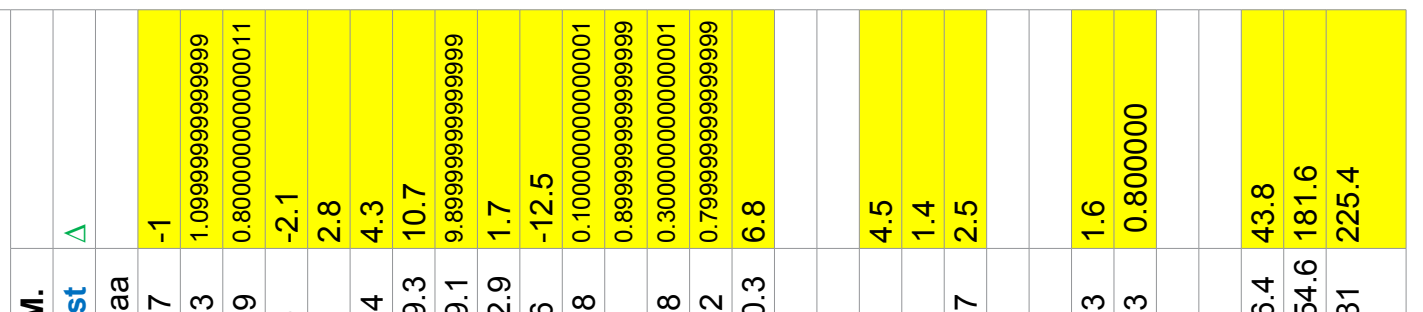

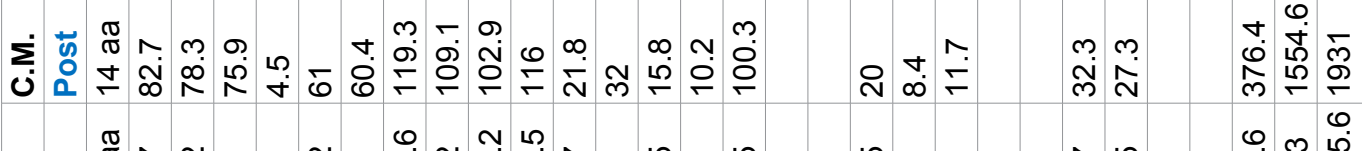

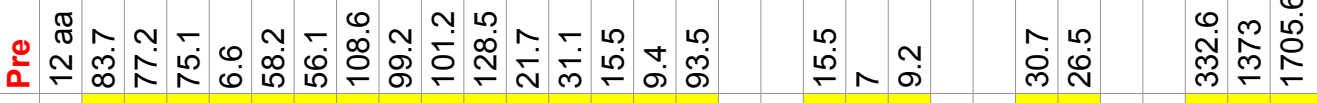
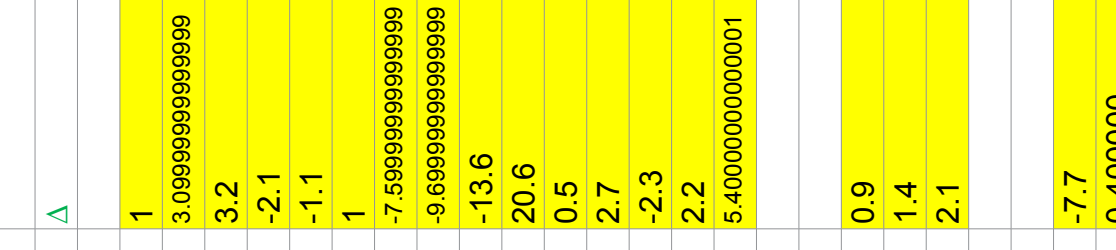

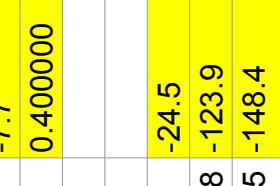

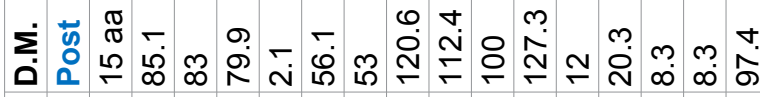

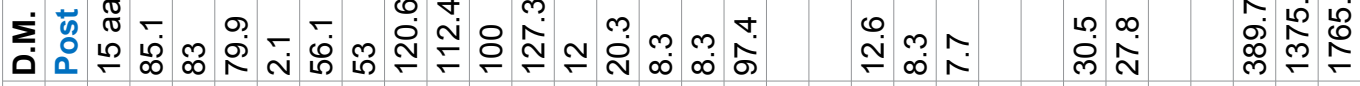

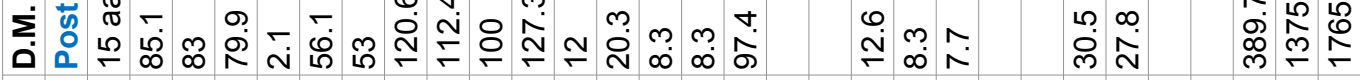

ก.
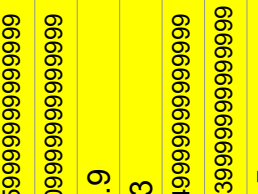

乐

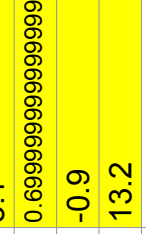

$\stackrel{m}{m} \stackrel{m}{\circ} \stackrel{m}{m}$

$\stackrel{\oplus}{r} \stackrel{m}{\forall}$

क क

j范然

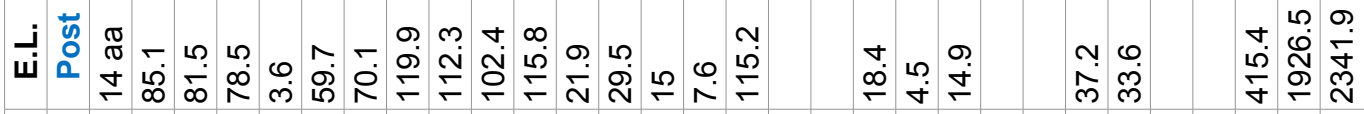

u

u

u

స ल

范

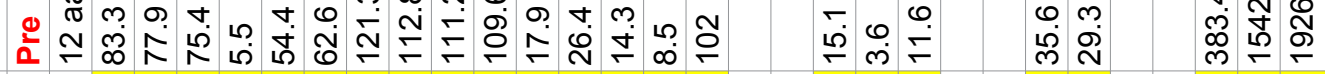

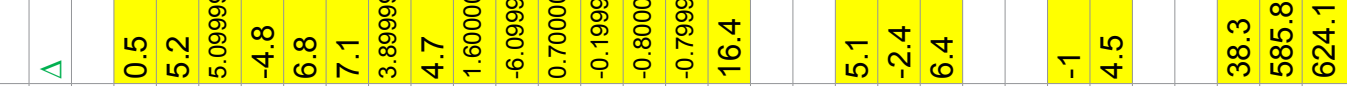

ن

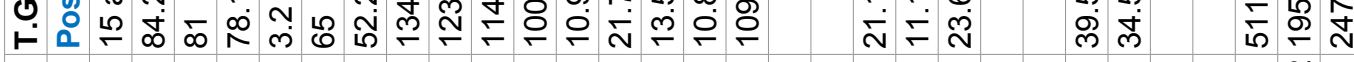

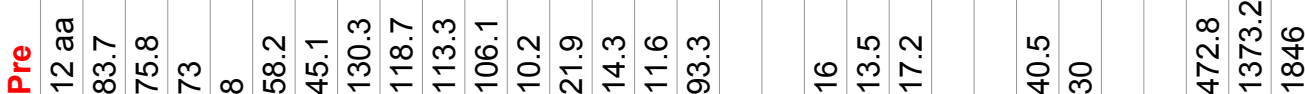

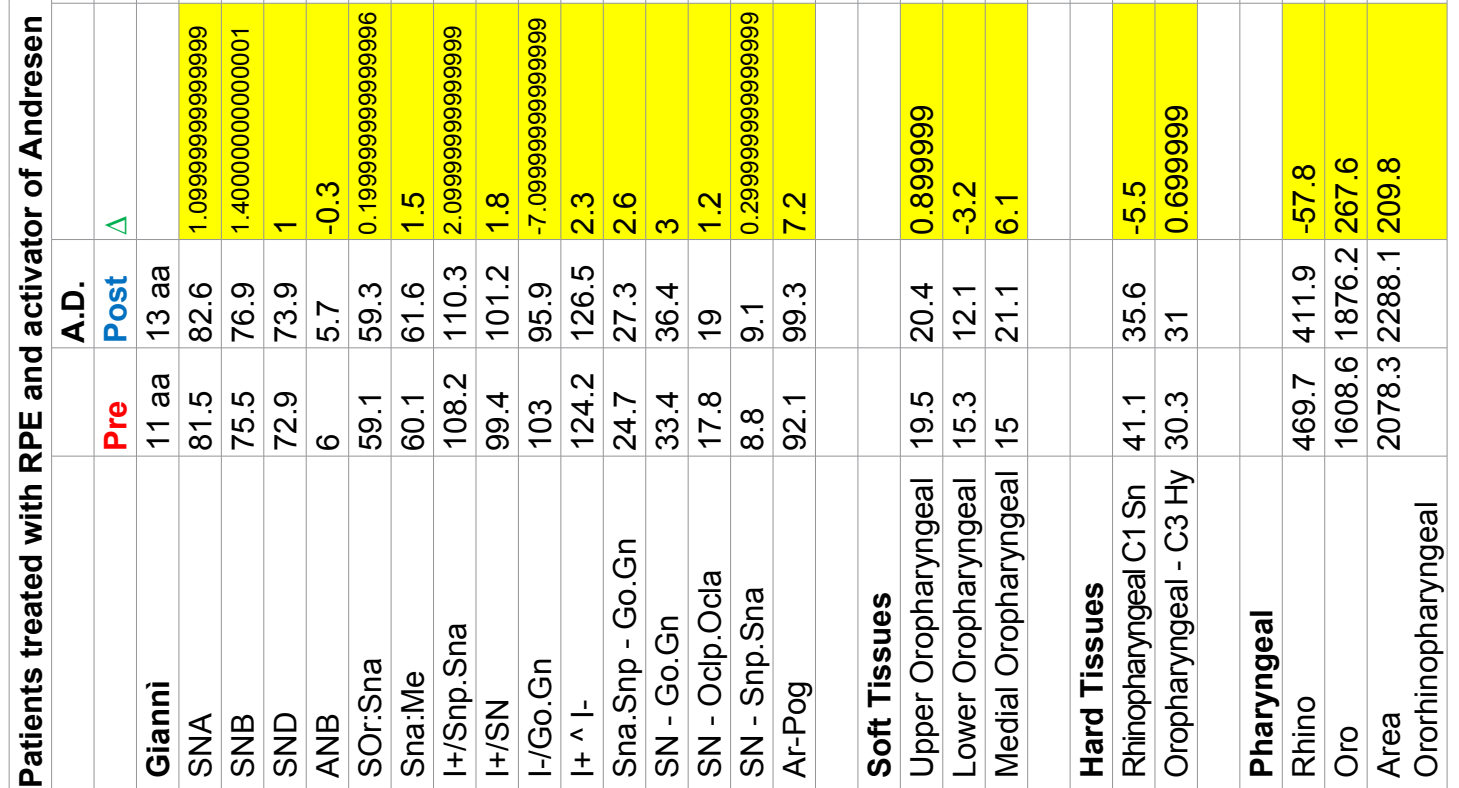



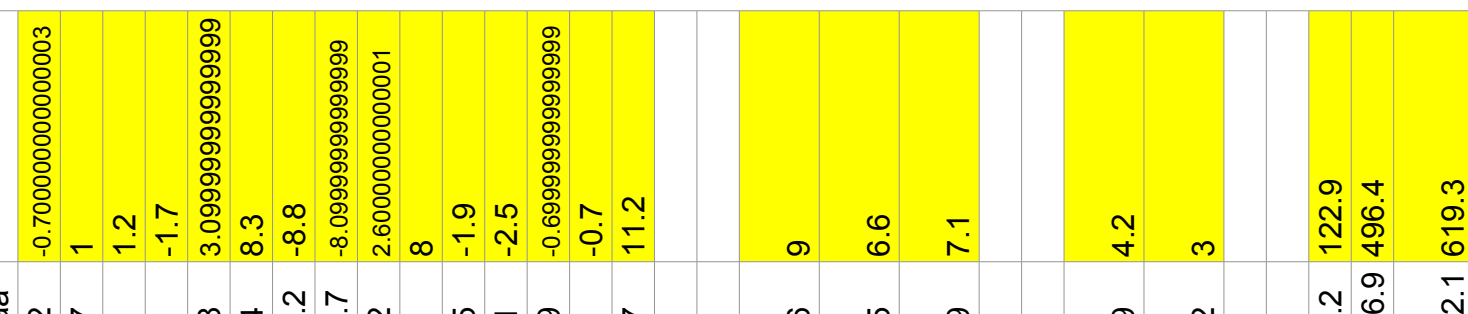

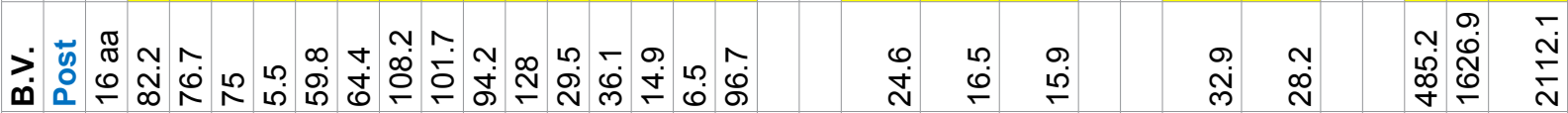

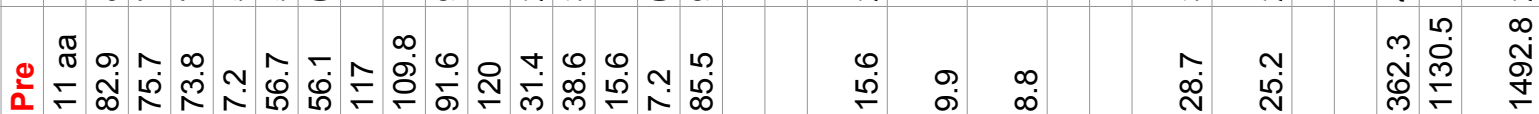

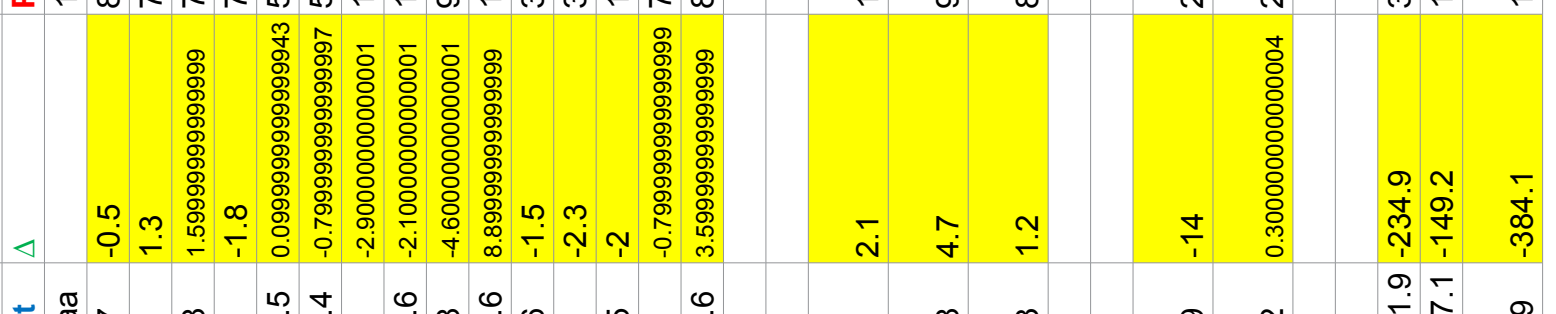

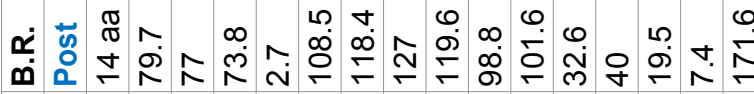

吾

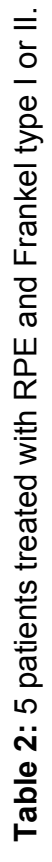

$\stackrel{\infty}{\stackrel{\infty}{\varphi}} \stackrel{\stackrel{m}{\sim}}{\stackrel{0}{*}}$

\ָ:

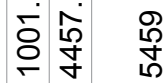

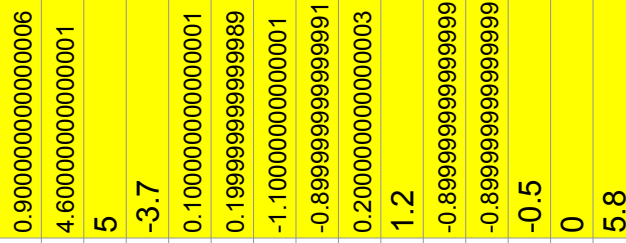

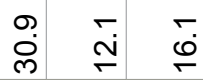

$\begin{array}{ll}\dot{0} & \dot{g} \\ \dot{\theta} & \dot{q}\end{array}$

cic

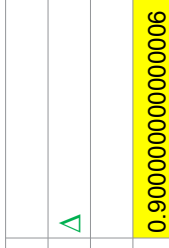

م.

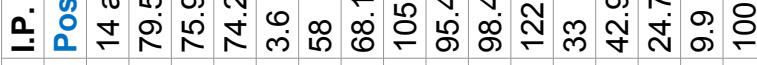

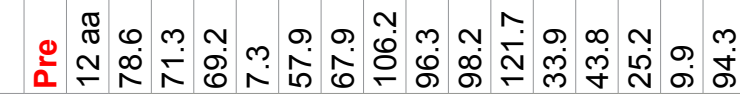

$\stackrel{m}{m} \stackrel{\infty}{\sim} \stackrel{m}{\sim}$

๗ֶ)

\section{(1)}

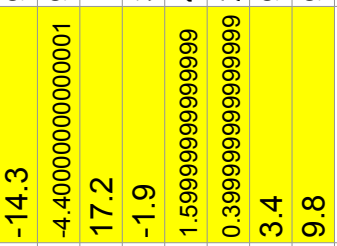

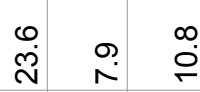

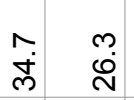

范

$\stackrel{\text { iे }}{\text { in }}$

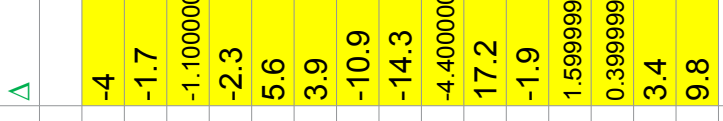

n $\overline{\mathrm{i}} \stackrel{\mathrm{N}}{ }$

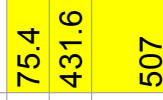

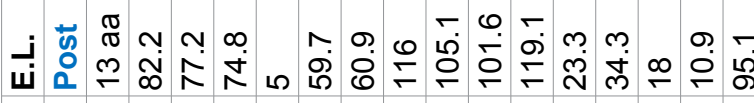

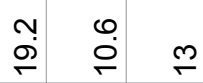

से $\stackrel{\substack{\infty \\ \infty}}{\infty}$

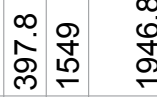

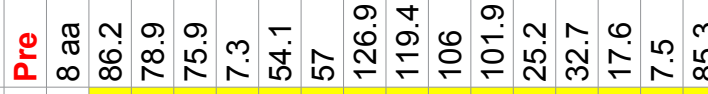

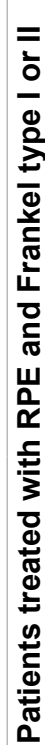

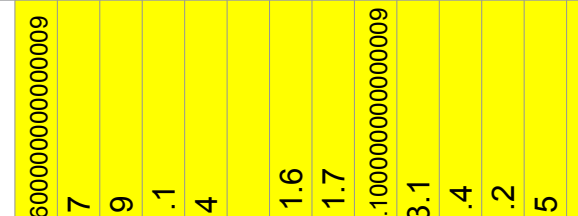

$\overline{\mathbf{o}}$
$\mathbf{0}$
$\mathbf{0}$
$\mathbf{0}$
$\mathbf{0}$

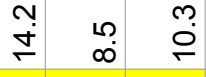

岕芒芒

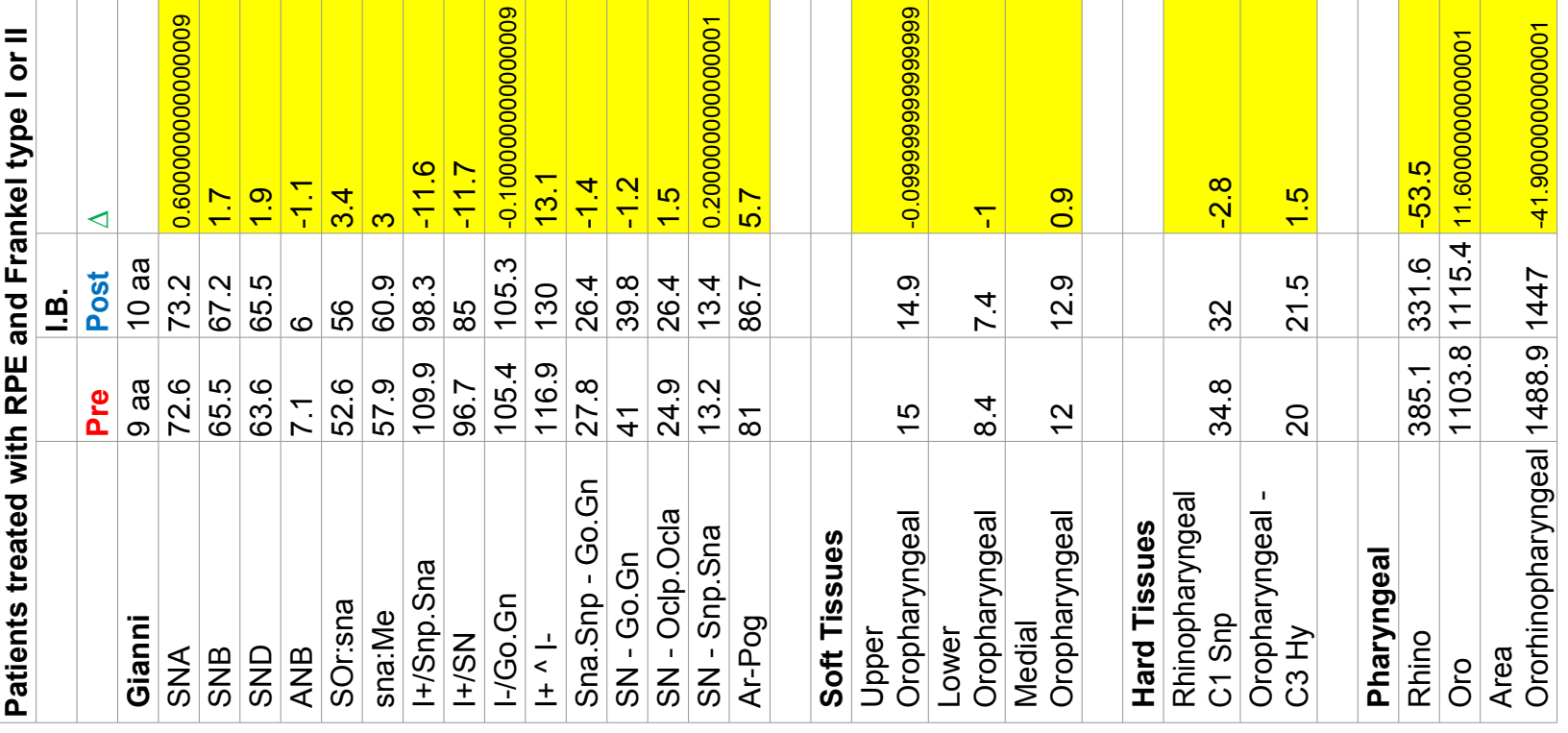




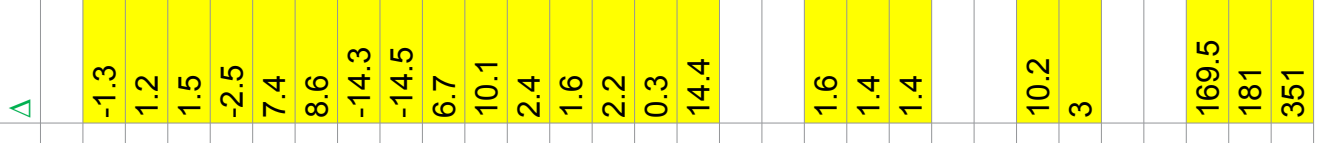

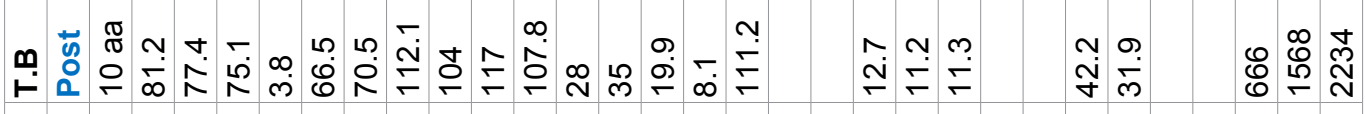

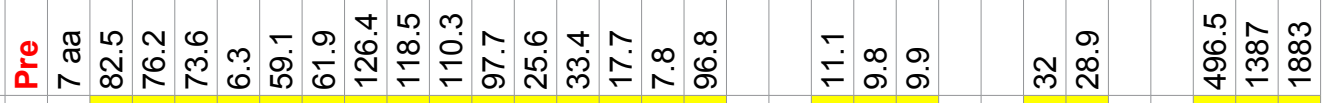

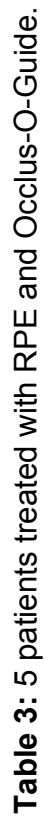

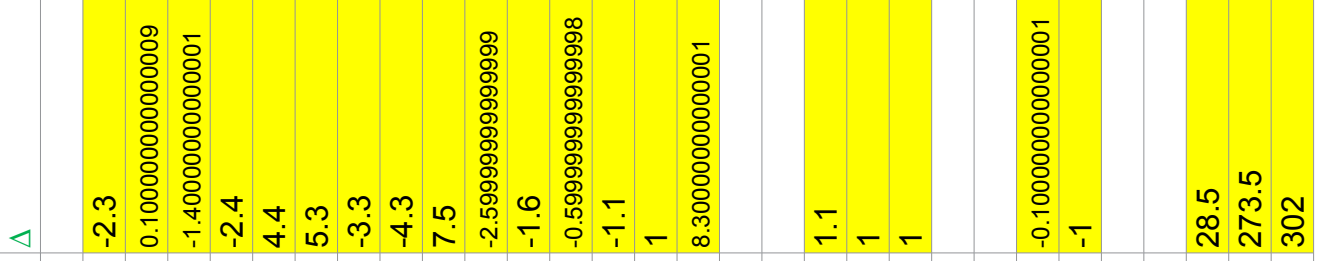

ن

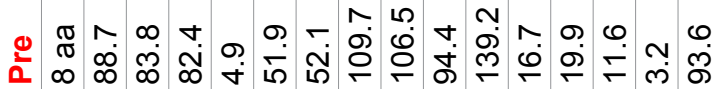

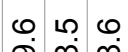
@ִ

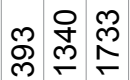

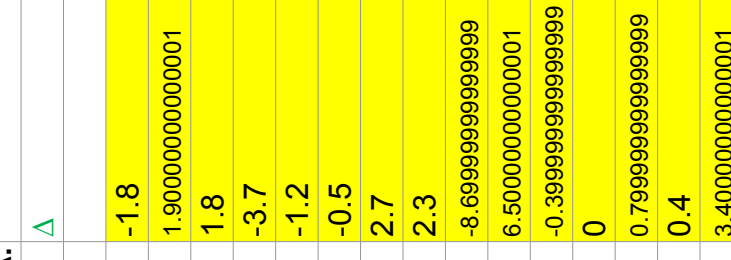

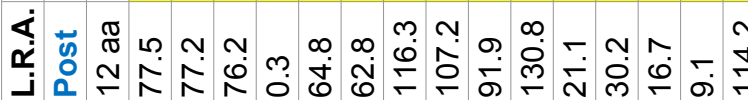

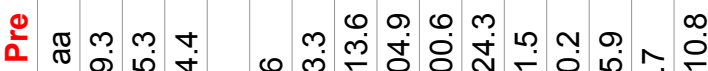

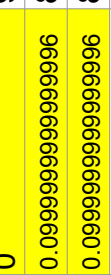

0

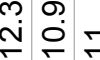

i $N$

i)
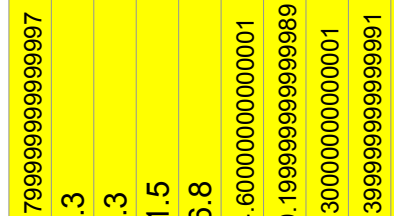

র்

$\stackrel{1}{\check{\tau}}$

กْi

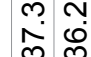

ำ 유 잉

$\dot{0} 0$

峁

.

เิ ญे ֻ

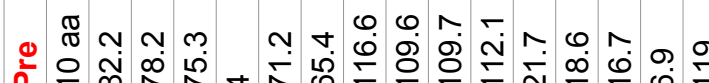

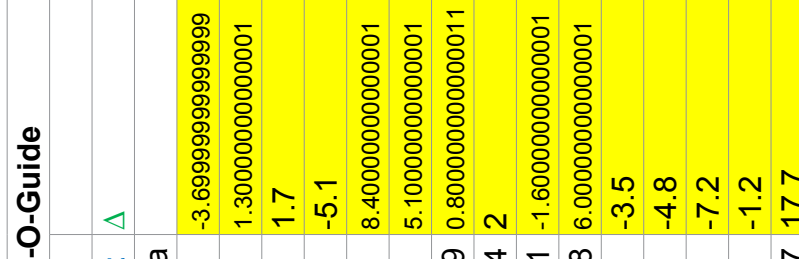

吾

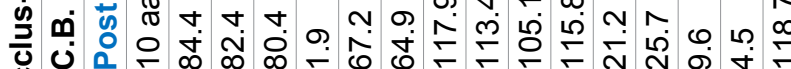

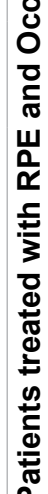

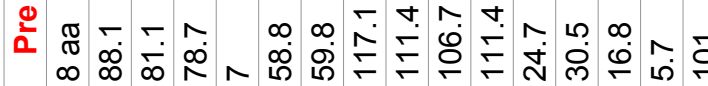

ヘิ ํํำ

гே 守

ᄂ $8 \infty$

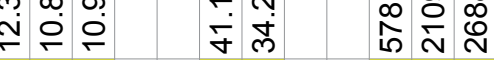

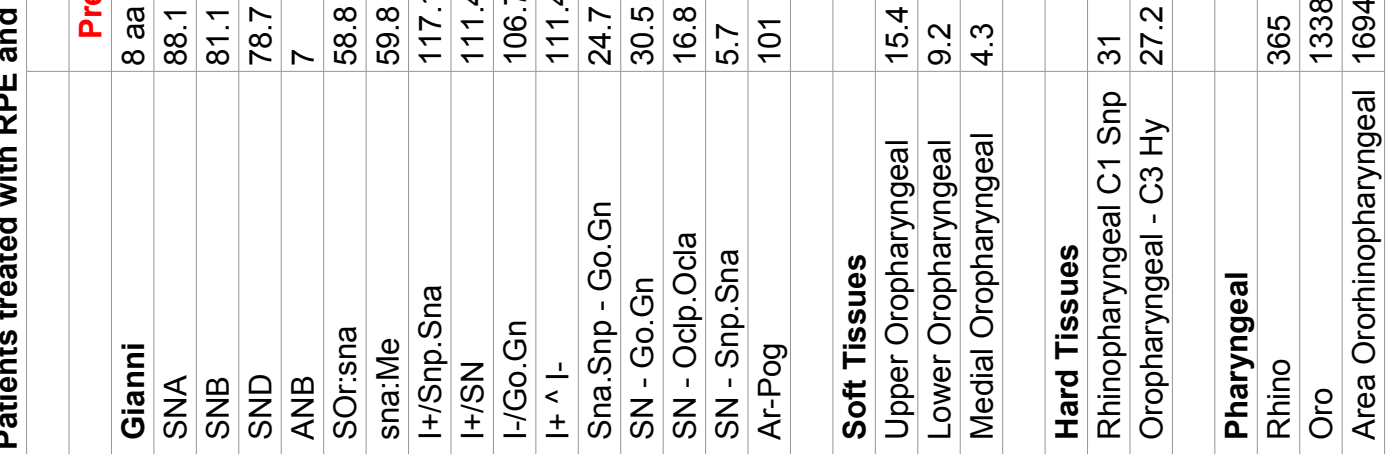


- A greater increase in the angle of divergence in cases treated with Andersen activator ( $\Delta$ Sna.snp-Go.Gn $=$ 1.58 a) compared to cases treated with Frankel ( $\Delta$ sia. snp-Go.Gn $\left.=-1.52^{\circ}\right)$; Student's test in this case showed a statistically significant difference $(p=0.006)$.

As far as upper airway analysis is concerned, we observe:

A greater increase in the depth of the upper portion of the oropharynx in patients treated with an activator of Andresen $(\Delta=2.94 \mathrm{~mm})$ and Frankel $(\Delta=3.86$ $\mathrm{mm}$ ) compared to patients treated with obstructive Occlus-O-Guides $(\Delta=-0.34 \mathrm{~mm})$; The $\mathrm{t}$ test student showed statistically significant differences $(p=0.03$ in comparison with patients treated with activator and patients treated with Occlus-O-Guide; $p=0.02$ in comparison with patients treated with Frankel and patients treated with Occlus- O-Guide.

A general tendency to decrease the length of the C1Sno segment expressing the depth of the upper portion of the pharynx (rhinopharynx).

A general tendency to increase the length of the C3-Hy segment expressing the depth of the lower tract from the pharynx.

A considerable dispersion of data (excessive standard deviation values) with respect to the rhino-pharyngeal and oro-pharyngeal area (and hence the total pharyngeal area).

Finally, the correlation coefficient of Pearson ( $r$ ) was calculated and it was shown: A strong correlation between the increase of the mandibular length (Ar-Gn) and the increase of the total pharyngeal area $(r=0.92)$. A strong correlation between the increase in the anterior upper vertical skeletal dimension (Sor-Sna) and the increase in the rhinopharyngeal area as evidenced in the Kinziger study [13] $(r=0.88)$. A moderate correlation $(r=0.56)$ between anterior lower vertical skeletal size (Sna-Me) and increased oropharyngeal area.

Based on the data collected and the statistical analysis conducted, as expected, the effects of the different types of mandibular thrust are overlapping with regard to the stimulation of mandibular growth: The activator seems to favor an increase in SNB angle compared to two other devices and the Occlus-O-Guide have a greater inhibitory effect on the upper jaw. In this regard the maxillo-mandibular divergence parameter should be considered: The RPE and Frankel treated samples are composed of hyperdivergent patients, so mandibular advance is inevitably countered by the increased divergence that tends to keep point $B$ backward. Patients treated with RPE and monoblock showed a statistically significant increase in skeletal divergence compared to patients treated with RPE and Frankel and this data confirms the therapeutic utility of Andresen's activator in the $2^{\text {nd }}$ hypodivergent skeletal classes. The upper part of the oropharynx (OSP-OSA) was more pronounced in the first two patient samples than the third with a statistically significant difference. No statistically significant differences were observed between the 3 samples with regard to the middle oropharyngeal tract (OMP-OMA). Moreover, Frankel would seem more effective than other devices in increasing the depth of the lower oropharynx (OIP-OIA).

Going to analyze correlations with the Pearson coefficient, there is a strong correlation ( $r=0.92)$ between mandibular length increase and total pharyngeal area increase. Therefore the stimulation of mandibular growth has a positive presence on the depths of the UAS.

The patient's skull posture is a factor that greatly influences the numerical values of the angular and linear parameters and of the calculated areas for studying the UAS; In this regard, a great advantage of the CBCT is the ability to orient the acquired volume of the anatomical structure to be studied according to the anatomical plans of interest, regardless of how the head of the patient is placed during the examination $[14,15]$.

The teleradiography of the skull in the latero-lateral projection allows only a sagittal and vertical evaluation of the UAS and must be associated with a teleradiography of the skull in postero-anterior projection, useful for defining, for example, the transverse extension of the nasal pits.

Although the teleradiography of the skull in the latero-lateral position is a simple, inexpensive execution of the diagnostic examination, which involves the patient's reduced exposure to ionizing radiation, it has a large two-dimensional limit that does not allow precise measurements on the three plans of space, as it allows the low dosage CBCT.

Moreover, it is often difficult to locate many cephalometric points of the skull in lateral projection due to the overlapping of numerous bone structures.

\section{Conclusion}

Treatment of mandibular skeletal classes II by mandibular thrust entails an increase in the post-operative extension of the posterior-anterior oropharynx that appears to be most affected by the action of these devices.

Effects of the three different types of mandibular thrusters on the oropharynx are substantially overlapping.

\section{References}

1. Farronato G, Salvato A, Amabile G, Pignataro O (1985) Correlazioni tra resistenze nasali e parametri cefalometrici nei respiratori orali. Atti del XX Congresso Nazionale della Società Italiana di Odontostomatologia e Chirurgia Maxillofacciale, Saint Vincent (AO) 26, 29.

2. Maspero C, Giannini L, Galbiati G, Kairyte L, Farronato G (2015) Upper airway obstruction in class II patients. Effects of Andresen activator on the anatomy of Pharyngeal airway passage. Cone Beam evaluation. Stomatologija 17: 124-130. 
3. McNamara JA Jr (1981) Components of class II malocclusion in children 8-10 years of age. Angle Orthod 51: 177202.

4. Muto T, Yamazaki A, Takeda S (2008) A Cephalometric evaluation of Pharyngeal airway space in patients with mandibular retrognathia and prognathia and normal subjects. Int J Oral Maxillofac Surg 37: 228-231.

5. Giannì E, Guastamacchia C (1962) Studio teleradiografico sulla forma e posizione della lingua in soggetti distrofici con la respirazione orale, nasale e mista. Raas Int Stom Pratica.

6. McNamara JA Jr (1973) Neuromuscular and skeletal adaptations to altered function in the orofacial region. Am J Orthod 64: 578-606.

7. Farronato G, Farronato D, Toma L, Bellincioni F (2010) A sintetic three dimensional craniofacial analysis. J Clin Orthod 44: 673-678.

8. Farronato G, Dominici AD, De Nardi S, Luini G, Dickers C, et al. (2008) Analisi cefalometrica 3D dei dieci punti con TC Cone Beam a basso dosaggio. Dentista Moderno Dicembre.
9. Nessi R, Viganò L (2004) Radiologia odontostomatologia. Edizione Piccin.

10. Perillo L, Cappabianca S, Montemarano M, Cristallo L, Negro A, et al. (2012) Craniofacial morphology and obstructive sleep apnoea-Hypopnoea Syndrome: A craniometric comparative analysis. Radiol Med 118: 648-659.

11. Ast DB, Carlos JP, Cons NC (1965) The prevalence and characteristics of malocclusion among senior high school students in upstate new york. Am J Orthod 51: 437-445.

12. Sfondrini G, Gandini P, Sfondrini F, Cacciafesta V, Fraticelli D (2008) Ortognatodonzia terapia. Edizioni Martina.

13. Kinzinger G, Czapka K, Ludwig B, Glasl B, Gross U, et al. (2011) Effects of fixed appliances in correcting angle class II on depth on the posterior airway space. J Orofac Orthop 72: 301-320.

14. Cozza P, Polimeni A, Ballanti F (2004) A modified monobloc for the treatment of obstructive sleep apnea in pediatric patient. Eur J Orthod 26: 523-530.

15. Ghodke S, Utreja AK, Singh SP, Jena AK (2014) Effects of twin block appliance on the anatomy of pharyngeal airway passage (PAP) in class II malocclusion subjects. Prog Orthod 15: 68. 